\title{
A multiphase model for reinforced concrete structures considering the concrete cracking
}

\section{Um modelo multifásico para estruturas em concreto armado considerando a fissuração do concreto}

M. P. FIGUEIREDO marcelo.porto@ufrgs.br

S. MAGHOUS samir.maghous@ufrgs.br

A. CAMPOS FILHO ${ }^{\circ}$ americo@ufrgs.br

\begin{abstract}
Assessing the global behavior of reinforced materials from the individual properties of their components has been the subject of a considerable amount of experimental and theoretical works in the last years. The so-called multiphase model is an alternative generalization of the homogenization method and it relies upon the idea that, at the macroscopic scale, the reinforced concrete is a geometrical superposition of the matrix phase (concrete) and the reinforcing phase (steel bars). This technique was already successfully employed in several geotechnical structures. Considering the particular case of concrete structures, Figueiredo et al [1] analyzed the mechanical behavior of reinforced concrete flat slabs under prescribed loading using the multiphase model in elastoplasticity. The present contribution extents a previously numerical code to account for concrete cracking based on a smeared crack approach. Comparison with direct simulation results emphasizes the advantage of such multiphase model in terms of reduced computational cost.
\end{abstract}

Keywords: multiphase model, elastoplasticity, concrete cracking, finite element method, reinforced concrete.

\section{Resumo}

Determinar o comportamento global de materiais reforçados a partir das propriedades individuais de seus componentes vem sendo tema de um considerável número de trabalhos experimentais e teóricos nos últimos anos. A modelagem multifásica é uma generalização alternativa do método de homogeneização cujo princípio básico consiste em descrever o concreto armado como a superposição geométrica da fase matriz (concreto) e da fase reforço (barras de aço). Esta técnica foi empregada com sucesso em uma série de trabalhos envolvendo estruturas geotécnicas. No caso da estruturas de concreto, Figueiredo et al (2009) estuda o comportamento mecânico de placas de concreto armado sob a ação de carregamento prescrito com o uso da modelagem multifásica em elastoplasticidade. No presente trabalho é acrescentado ao modelo previamente desenvolvido o algoritmo que leva em conta a fissuração do concreto baseado no modelo de fissuras distribuídas apresentado por Hinton (1988). São realizadas comparações com simulações diretas clássicas visando salientar as vantagens do modelo como a redução significativa do custo computacional.

Palavras-chave: modelo multifásico, elasto-plasticidade, fissuração do concreto, método dos elementos finitos, concreto armado.

\footnotetext{
Programa de Pós-Graduação em Engenharia Civil, Universidade Federal do Rio Grande do Sul, marcelo.porto@ufrgs.br, Av. Osvaldo Aranha 99, Porto Alegre, Brasil

b Programa de Pós-Graduação em Engenharia Civil, Universidade Federal do Rio Grande do Sul, samir.maghous@ufrgs.br, Av. Osvaldo Aranha 99, Porto Alegre, Brasil

c Programa de Pós-Graduação em Engenharia Civil, Universidade Federal do Rio Grande do Sul, americo@ufrgs.br, Av. Osvaldo Aranha 99, Porto Alegre, Brasil
} 


\section{Introduction}

The capacity of predicting the essential characteristics that govern the behavior of materials reinforced by stiff linear inclusions from the properties of the individual components still remains a major concern in structural engineering of composite materials, and a significant number of works has been dedicated to this subject in the last decades.

As far as the finite element modeling of reinforced concrete structures is concerned, steel bars are traditionally accounted for through three ways (CEB [2]): 1) by means of a continuous equivalent model as often used in the case of plates and shells, substituting the dense reinforcement by equivalent layers, 2) through a discrete modeling in which the steel bars are represented by one-dimensional elements frequently associated with appropriate adherence elements, and 3) through the so-called "embedded model" where each bar is considered as a stiffer linear inclusion embedded within the element of concrete matrix, thus resulting in an element stiffness equal to the sum of concrete matrix and steel bar contribution. However such approaches can come up against serious numerical difficulties when the number of bars involved in the structure becomes higher. Indeed, the computational cost may eventually be prohibitively large since three-dimensional analysis is generally needed to take into account interactions between concrete matrix and inclusions properly and since non-linear constitutive models, such as plasticity, have to be utilized in order to obtain relevant results.

An alternative approach called multiphase model was recently developed, providing a mechanically consistent framework to analyze the behavior of structures made up of materials reinforced by linear continuous inclusions. The general formulation of the model is presented in Sudret [3] together with applications in the field of geotechnical engineering. Extensions of the multiphase model have been introduced by Bennis [4] and later by Hassen [5]. The method has been applied to a large variety of problems involving reinforced soils such as reinforced earth, micropile networks and rock-bolted tunnels may be found in de Buhan and Sudret [6] or Hassen and de Buhan [7]. The purpose of the present contribution is to present a consistent mechanical framework, providing a description of concrete reinforced by steel bars, as a multiphase system. Conceived as an extension of the homogenization theory, the multiphase model is in its essence based on the mixture theory due to the pioneer work of Truesdell and Toupin [8]. Unlike the description of the material at the microscopic scale in which both constituents (matrix and reinforcement) occupy geometrically distinct domains of space, the multiphase model is based on a macroscopic description of the composite medium as the superposition of several continua [9].

In this context, Manzoli et al. $[10,11]$ recently proposed a model for 3D analysis of structural elements of reinforced concrete, in which the latter is described using mixture theory concepts. From a theoretical viewpoint, even the mentioned model is closely connected to that developed in this contribution, there is however a fundamental difference regarding how the interaction matrix/reinforcement is accounted for. The modeling adopted in $[10,11]$ assumes a parallel layout, meaning that all constituents share the same strain field. The slip effect due to the bond degradation at the interface matrix/reinforcement is introduced in a heuristic way. In contrast, the formulation of the multiphase model based on the virtual work method, incorporates in a consistent way the matrix/reinforcement interaction. Starting from different kinematics for each phase, the equations governing such a model are developed in the context of elastoplasticity, account automatically for any slippage phenomenon occurring between the matrix and the reinforcement.

\section{The multiphase model for reinforced concrete}

\subsection{Description of the model}

Considering the reinforced concrete as a matrix of concrete with steel bars arranged periodically (Figure [1]) and the typical size of the structure being significantly greater

\section{Figure 1 - Description of the reinforced material, Hassen (5)}

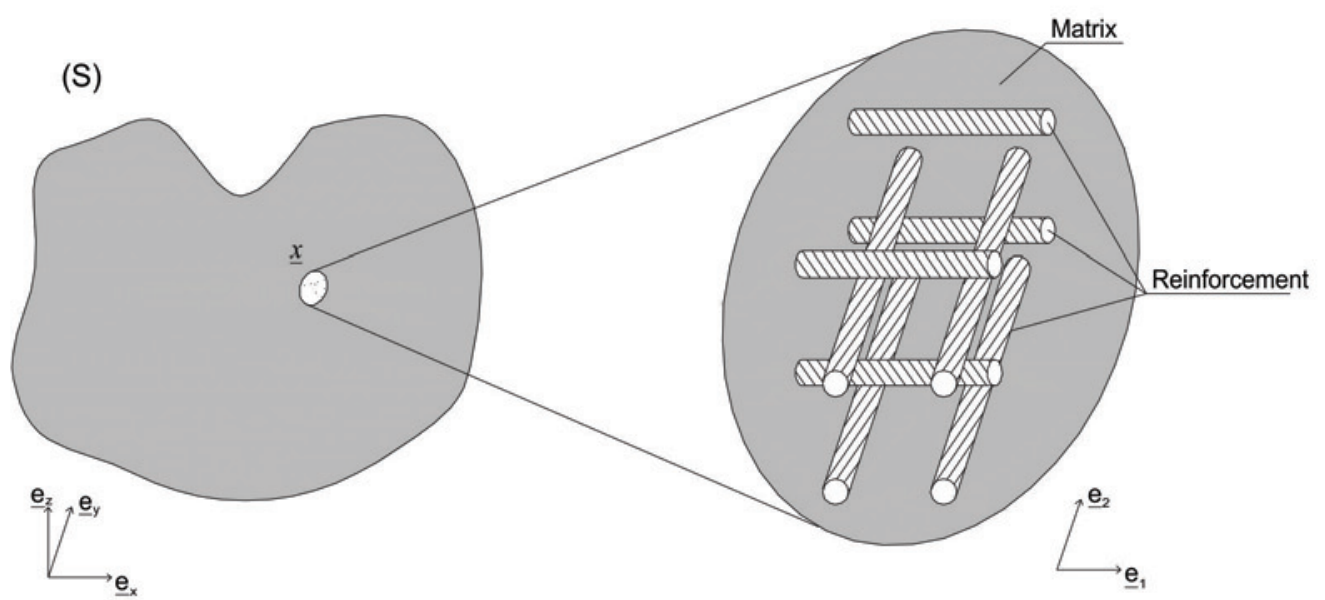




\section{Figure 2 - Description of the material with the matrix phase and two reinforcement phases}

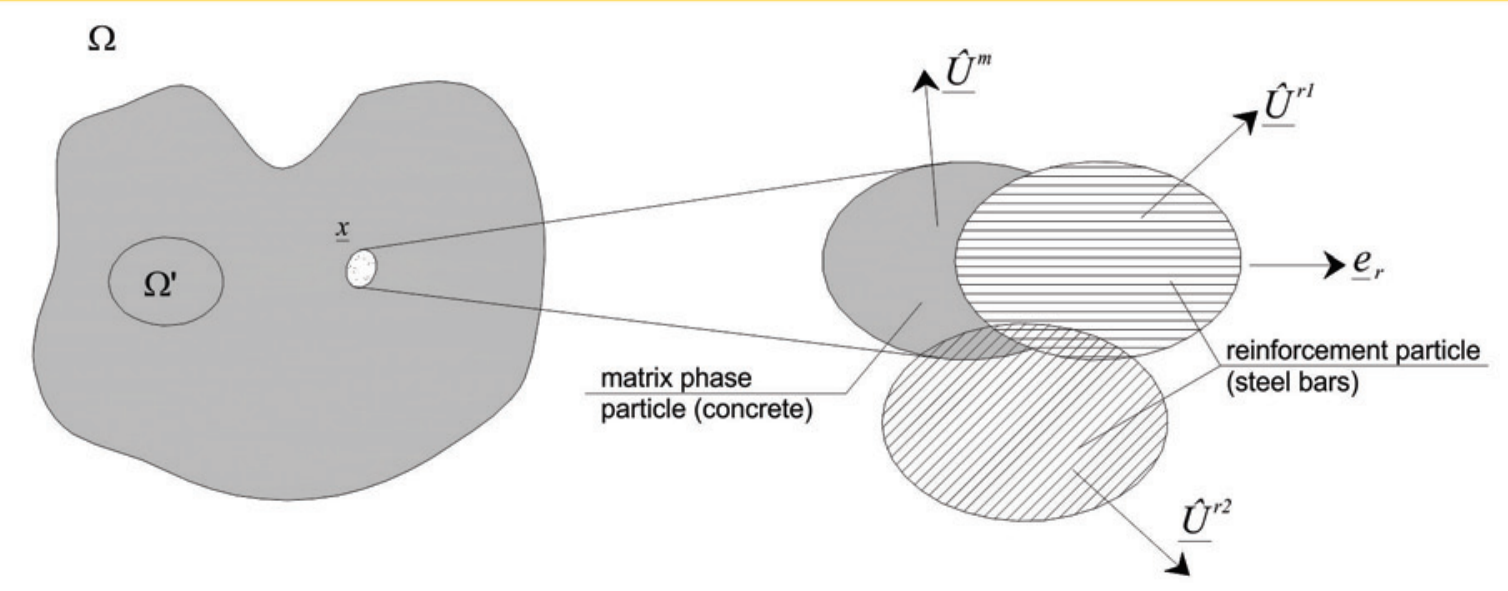

than the diameter of the inclusions and their spacing. Also consider the reinforced concrete as homogenous medium.

$$
d \Omega(\underline{x})=d \Omega^{m}(\underline{x}) \bigcup_{r=1, \ldots N} d \Omega^{r}(\underline{x})
$$

In this way, the steel bars are grouped in a finite number of $\mathrm{N}$ different families, each one of these families characterized by a direction given by a unit vector $\underline{e}_{r}(r=1, \ldots, N)$. The number of reinforcement families will be the same to the number of directions in which the bars are disposed (Figure [2]).

\subsection{Efforts behavior}

The matrix phase is modelled as Cauchy continuum. It can be shown that the internal forces are described by a second-order symmetrical tensor denoted by $\sigma^{m}$. This quantity will be referred to as the matrix phase stress tensor.

It is admitted that the inclusions are assumed to take only tensilecompressive forces, that is, shear forces and bending moments are disregarded. Hassen [5] applies the multiphase model taking into account that the inclusions takes these efforts. So, the variable that describes the internal forces in the reinforcement phase turns out to be a scalar stress, noted $\sigma^{r}$.

Finally, due to the superposition of $\mathrm{N}+1$ particles in each point, body forces, $\underline{I}^{j}$, are introduced to account for the interaction between phases.

The external forces applied onto a geometrical volume $\mathrm{W}$ are prescribed in each phase $j$ separately, and consists in:

a) Body forces denoted by $\rho^{j} \underline{F}^{j}$ (gravity) exerted by the outside of W b) Tractions $\underline{T}^{j}$ applied at the boundary $\partial \Omega$.

The inertial forces are computed by means of the phase acceleration fields denoted by $\gamma^{j}$.

\subsection{Equations of motion}

In this way, the equations of motion of the multiphase model are given, in agreement with Sudret [3], for each phase separately as follows.

$$
\operatorname{div} \underline{\underline{\sigma}}^{m}(\underline{x})+\rho^{m}(\underline{x})\left(F^{m}(\underline{x})-\gamma^{m}(\underline{x})\right)+\sum_{r=1}^{N} \underline{I}^{r}(\underline{x})=0
$$

$$
\operatorname{div}\left(\sigma^{r}(\underline{x}) \underline{e}_{r} \otimes \underline{e}_{r}\right)+\rho^{r}(\underline{x})\left(F^{r}(\underline{x})-\gamma^{r}(\underline{x})\right)-\underline{I}^{r}(\underline{x})=0, \quad r=1, \ldots N
$$

The corresponding boundary conditions are

$$
\underline{T}^{m}(\underline{x})=\underline{\sigma}^{m}(\underline{x}) \cdot \underline{n}(\underline{x})
$$

$$
\underline{T}^{r}(\underline{x})=\sigma^{r}(\underline{x})\left(\underline{e}_{r} \otimes \underline{e}_{r}\right) \cdot \underline{n}(\underline{x}), \quad r=1, \ldots N
$$

\subsection{Perfect bounding model}

Sudret [3] and de Buhan and Sudret [6] present a particular case of the two-phase model where is admitted the perfect bonding hypothesis: all phases have the same displacement field. This model is going to allow to treat problems of reinforced concrete in what is supposed to be no slippage between the steel bars and the concrete matrix. So:

$$
\underline{\xi}^{m}=\underline{\xi}^{r} \equiv \underline{\xi}
$$


Taking into account the perfect bounding hypothesis, is introduced, with no ambiguity, the total strain tensor:

$$
\left.\underline{\underline{E}}=\frac{1}{2} \underline{\underline{\operatorname{grad} \xi}}+{ }^{t} \underline{\underline{\operatorname{grad} \xi}}\right)
$$

The compatibility equations between the phase strain variables are:

$$
\underline{\underline{\varepsilon}}^{m}=\underline{\underline{\epsilon}} ; \quad \varepsilon^{r}=\underline{\underline{\epsilon}}:\left(\underline{e}_{r} \otimes \underline{e}_{r}\right) \equiv \epsilon_{r r}
$$

In this model, the system kinematics is described by a single displacement field $x$. Bennis [4] carries out the application of the model to geotechnical structures considering the interaction between matrix and reinforcement.

It is thus relevant do derive global equations of motion for the whole system. These equations are obtained by summing up Eq. (2), (3) and the Eq. (4), (5) respectively. Introducing the following notation:

$$
\rho \underline{F}=\sum_{j} \rho^{j} \underline{F}^{j} ; \underline{T}=\sum_{j} \underline{T}^{j} ; \rho \underline{\gamma}=\sum_{j} \rho^{j} \underline{\gamma}^{j}
$$

$$
\underline{\underline{\Sigma}}=\underline{\underline{\sigma}}^{m}+\sum_{r=1}^{N} \sigma^{r} \underline{e}_{r} \otimes \underline{e}_{r}
$$

with $j \in\{m, r=1, \ldots N\}$, one gets:The tensor of total stress $\underline{\underline{\Sigma}}$

$$
\operatorname{div} \underline{\underline{\Sigma}}+\rho(F-\underline{\gamma})=\underline{0}
$$

$$
\underline{T}=\underline{\underline{\Sigma}} \cdot \underline{n}
$$

The tensor of total stress appears to be the sum of the partial tensor in the matrix phase and the uniaxial partial stress tensor in the reinforcement phase. With this notation, the constitutive Eq. (11) and (12) reduce to those of the classical Cauchy continuum. To complete the description of the perfect bonding model, global constitutive equation relating $\Sigma$ and $\in$ are derived. One can easily prove that the global fourth-order $\overline{\overline{\text { tensor }}}$ of elastic moduli $A$ satisfying $\underline{\underline{\Sigma}}=\underline{\underline{A}}: \underline{\underline{\underline{ }}}$ in the elastic domain write:

$$
\underline{\underline{\underline{\underline{A}}}}=\underline{\underline{\underline{\underline{a}}}}^{m}+\sum_{r=1}^{N} a^{r} \underline{e}_{r} \otimes \underline{e}_{r} \otimes \underline{e}_{r} \otimes \underline{e}_{r}
$$

where the global tensor of elastic moduli is decomposed additively in a contribution of the matrix phase and a contribution of each reinforcement phase. It appears clearly that the directions $\underline{e}_{r}$ are privileged, what is seen in the anisotropic characteristic of the behavior. Equilibrium equations and constitutive laws have been derived, making it possible to solve boundary value problems. In order to model real reinforced structures, it is now necessary to connect the phase constitutive laws with the material characteristics of the concrete and inclusions, de Buhan and Sudret [6] assumed that the volume fraction $\eta^{r}$ of the inclusion is small compared to one:

- The matrix phase constitutive law is identified with that of the concrete.

- Supposing that the inclusions take axial force only it is possible to calculate the reinforcement phase stiffness as:

$$
a^{r}=\eta^{r} \cdot E^{i n c}
$$

where $E^{i n c}$ is the Young's modulus of the steel bars.

\section{Numerical implementation of the model}

The implementation formulated here follows the steps presented by Sudret [3], Hassen [5] and de Buhan and Sudret [6].

\subsection{Description of the model}

In case of perfect bonding, considering a kinematically admissible virtual displacement field $\underline{\xi}$ and its associated linear strain field $\underline{\hat{\varepsilon}}$, the principle of virtual ${ }^{-}$work, derived from Eq. (11) and (12), satisfies:

$$
\int_{\Omega} \underline{\underline{\Sigma}:} \underline{\hat{\varepsilon}} d \Omega-\int_{\Omega} \rho F \cdot \underline{\hat{\xi}} d \Omega-\int_{\partial \Omega} \underline{T}^{d} \cdot \underline{\hat{\xi}} d S=0
$$

Relating the elastic strain to the phase stress by $\underline{\underline{\sigma}}^{m}=\underline{\underline{a}}^{m}:\left(\underline{\underline{\varepsilon}}^{m}-\underline{\underline{\varepsilon}}_{p}^{m}\right)$ and $\sigma^{r}=a^{r}\left(\varepsilon^{r}-\varepsilon_{p}^{r}\right)$ and substituting in Eq. (11) and using the Eq. (8), the first term in Eq. (15) may be rewritten as follows:

$$
\int_{\Omega} \underline{\underline{\Sigma}}: \underline{\underline{\hat{\varepsilon}}} d \Omega=\int_{\Omega}\left[\underline{\underline{\underline{A}}}: \underline{\underline{\varepsilon}}-\underline{\underline{a}}_{\underline{\underline{a}}}^{m}: \underline{\varepsilon}_{p}^{m}-a^{r r} \underline{\varepsilon}_{p} \underline{\underline{e}}_{r} \otimes \underline{\underline{e}}_{r}\right]: \underline{\underline{\hat{\varepsilon}}} d \Omega \text { (16) }
$$

The geometric volume is discretized into $N_{e}$ elements. The displacement field $x$ in each element $n_{e}$ is approximated as follows

$$
\forall x \in v^{e}, \xi(x)_{v^{e}}=\mathbf{N}_{e}(\underline{x}) \cdot \underline{u}_{e}
$$




$$
\underline{\varepsilon}=\mathbf{B}_{e}(\underline{x}) \cdot \underline{u}_{e}
$$

\subsection{Plastic integration algorithm}

Due to the non-linearity of the phases' constitutive laws, the loading path is divided into load increments noted by $\underline{\mathrm{D}} \mathrm{F}_{j}^{\mathrm{ext}}$. For each load step, the problem is solved by an iterative algorithm.

where the matrix $\mathbf{B}_{e}$ contains partial derivatives of the shape functions with respect to the coordinates. Consequently, the matrix phase stress vector is:

$$
\underline{\sigma}^{m}=\mathbf{d}^{m} \cdot\left(\underline{\varepsilon}-\underline{\varepsilon}_{p}^{m}\right)
$$

It is introduced now an additional notation for dealing with the reinforcement phase. Let us denote by $\underline{\mathrm{e}}_{\mathrm{r}}$ the vector of the six components of $\underline{e}_{r} \otimes \underline{e}_{r}$. The compatibility Eq. (7) can be rewritten as:

$$
\varepsilon^{r}={ }^{t} \underline{\mathbf{e}}_{\mathbf{r}} \cdot \underline{\varepsilon}={ }^{t} \underline{\varepsilon} \cdot \underline{\mathbf{e}}_{\mathbf{r}}
$$

Substituting the above equations in the principle of virtual work (15) and using (16), one gets the discretized formulation, which leads to the usual linear system yielding the global vector of nodal displacement $\underline{U}$.

$$
\mathbf{K} \cdot \underline{U}=\underline{F}^{e x t}+\underline{F}_{p}^{m}+\underline{F}_{p}^{r}
$$

The global stiffness matrix $\mathbf{K}$ turns out to be:

$$
\mathbf{K}=\sum \int_{v^{e}}{ }^{t} \mathbf{B}_{e}\left(\mathbf{d}^{m}+\sum_{r=1}^{N} a^{r} \underline{\mathbf{e}}_{\mathbf{r}} \cdot{ }^{t} \underline{\mathbf{e}}_{\mathbf{r}}\right) \mathbf{B}_{e} d v^{e}
$$

the terms in the right-hand side of Eq. (21) are the external load vector:

$$
F^{e x t}=\sum\left(\int_{v^{e}}{ }^{t} \mathbf{N}_{e} \cdot \underline{\rho F} d v^{e}+\int_{\partial \Omega \cap v^{e}} \mathbf{N}_{e} \cdot \underline{T}^{d} d v^{e}\right)
$$

and the vector of plastic forces associated to each phase:

$$
\underline{F}_{p}^{m}=\sum \int_{v^{e}}{ }^{t} \mathbf{B}_{e} \cdot \mathbf{d}^{m} \cdot \underline{\varepsilon}_{p}^{m} d v^{e}
$$

$$
\underline{F}_{p}^{r}=\sum \int_{v^{e}} \sum_{r=1}^{N} a^{r} \varepsilon_{p}^{r t} \mathbf{B}_{e} \cdot \underline{\mathbf{e}}_{\mathbf{r}} d v^{e}
$$

Denoting by $\left\{\underline{U}_{n}, \underline{\underline{\sigma}}_{n}^{m}, \sigma_{n}^{r}, \underline{\underline{\varepsilon}}_{n}, \underline{\underline{\varepsilon}}_{p, n}^{m}, \varepsilon_{p, n}^{r}\right\}$ the set of state variables describing the system after load step $n$. For each variable $\chi$ in this set, let us write:

$$
\Delta \chi_{n}=\chi_{n+1}-\chi_{n}
$$

Let us apply the load increment $\underline{D} F_{j}^{\text {ext }}$. The corresponding displacements increment $\underline{\mathrm{U}}_{n}$ is obtained from the global equilibrium.

$$
\mathbf{K} \cdot \underline{U U}_{n}=\underline{\Delta F}_{n}^{e x t}+\underline{\Delta F}_{p, n}
$$

where $\Delta F_{p, n}=\Delta F_{p, n}^{m}+\Delta F_{p, n}^{r}$ is the vector of plastic nodal forces. These forces are unknown, since the plastic strain increments $\left\{\underline{\underline{\varepsilon}}_{p, n}^{m}, \varepsilon_{p, n}^{r}\right\}$ resulting from the load increment $\underline{\mathrm{D}} \underline{F}_{n}^{\mathrm{ext}}$ are still unknown. The latter have to be determined in such a way that the elastoplastic constitutive laws are satisfied in each Gauss point of the mesh.

The goal is achieved by using an iterative procedure. Starting from: $\underline{\underline{\Delta \varepsilon}}_{p, n}^{m}(0)=\Delta \varepsilon_{p, n}^{r}(0)=0$ at every Gauss point, sucessive evaluations $\left\{\underline{\varepsilon}_{p, n}^{m}(i), \varepsilon_{p, n}^{r}(i)\right\}$ of the plastic strains are calculated until convergence.

Suppose that $\left\{\underline{\varepsilon}_{p, n}^{m}(i-1), \varepsilon_{p, n}^{r}(i-1)\right\}$ is known at each Gauss point, the vector of plastic forces calculated by (22) and (23) being $\Delta F_{p, n}^{m}(i-1)$ and $\Delta F_{p, n}^{r}(i-1)$. The iteration $i$ consists first in computing the increment of nodal displacement $\underline{\Delta U}_{n}(i)$ satisfying:

$$
\mathbf{K} \cdot \underline{\Delta U}_{n}(i)=\underline{\Delta F}_{n}^{e x t}+\underline{\Delta F}_{p, n}(i-1)
$$

Following the global calculation yielding the displacement vector $\underline{\mathrm{DU}}_{n}(i)$, the constitutive laws have been checked locally in each Gauss point. The original point of the present implementation is the separate treatment of each individual phase. The power of the multiphase approach is thus totally exploited. The classical return mapping algorithm, Simo and Hughes [12], is applied in each Gauss point as follows:

At first, trial stress states are calculated for each phase by freezing the plastic strains resulting from the load increment. Then the phase yield criteria are evaluated separately. If they are negative, 
no additional plastic strain has developed due to $\underline{D} F_{n}^{\text {ext. }}$. If not, a closest-point projection of the trial states onto their respective yield surfaces is performed

For the matrix phase, this leads to solving the following set of equations:

$f^{m}\left(\underline{\underline{\sigma}}^{n+1}(i)\right)=0$

$$
\underline{\underline{\sigma}}^{n+1}(i)=\underline{\underline{\sigma}}_{n+1}^{t r i a l, m}(i)-\underline{\underline{\underline{a}}}^{m}: \underline{\underline{\Delta \varepsilon}}_{p, n}^{m}(i)
$$

$$
\underline{\underline{\Delta \varepsilon}}_{p, n}^{m}(i)=\Delta w_{i}\left(\frac{\partial g^{m}}{\partial \underline{\underline{\sigma}}^{m}}\right)
$$

Considering now the reinforcement phase, the yield criterion can be written as $f^{r}\left(\sigma^{r}\right)=\sigma^{r}-\sigma_{o}^{r}$ due to the one-dimensional formulation. The solution for the projection problem and the related plastic strain increment is:

$$
\sigma_{n+1}^{r}(i)=\left\{\begin{array}{lll}
\sigma_{o}^{r} & \text { if } & \underline{\underline{\sigma}}_{n+1}^{\text {trial, } r}(i) \geq \sigma_{o}^{r} \\
-\sigma_{o}^{r} & \text { if } & \underline{\underline{\sigma}}_{n+1}^{\text {trial }, r}(i) \leq-\sigma_{o}^{r}
\end{array}\right.
$$

$$
\Delta \varepsilon_{p, n}^{r}(i)=\frac{\sigma_{n+1}^{\text {trial } r}(i)-\sigma_{n+1}^{r}(i)}{a^{r}}
$$

\subsection{Failure criterion}

The strength of concrete under multiaxial states of stress may be estimated from the so-called Ottosen failure criterion given by Eq. 34, CEB [13]. It is considered that the plasticity convex surface is homothetic to the failure convex surface.

$$
\alpha \frac{J_{2}}{f_{c m}^{2}}+\lambda \frac{\sqrt{J_{2}}}{f_{c m}}+\beta \frac{I_{1}}{f_{c m}}-1=0
$$

where

$\lambda=c_{1} \cos \left[1 / 3 \arccos \left(c_{2} \cos 3 \theta\right)\right], \quad \cos 3 \theta \geq 0 ;$

$\lambda=c_{1} \cos \left[\pi / 3-1 / 3 \arccos \left(-c_{2} \cos 3 \theta\right)\right], \quad \cos 3 \theta<0$;

$\cos 3 \theta=\frac{3 \sqrt{3}}{2} \frac{J_{3}}{J_{2}^{3 / 2}}$.

\section{Figure 3 - Stress-strain diagram for uniaxial compression}

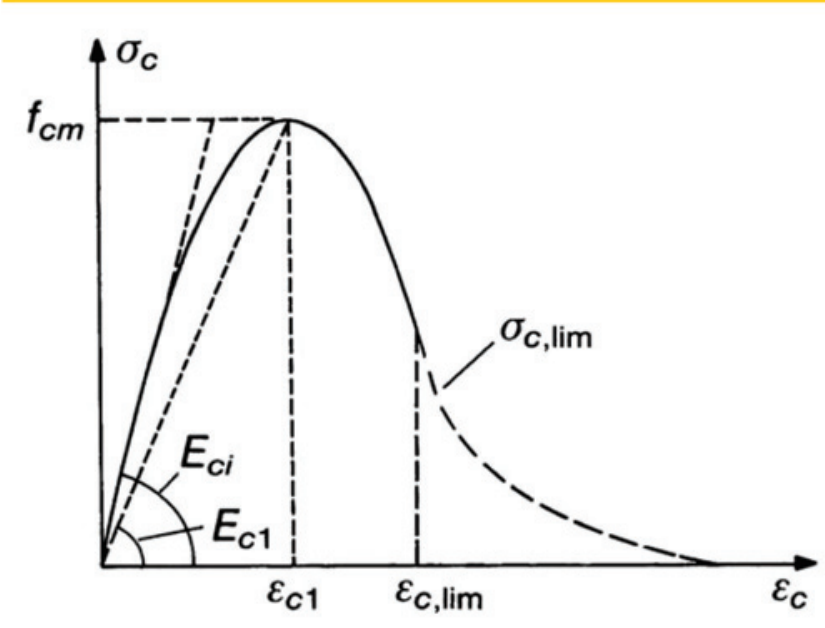

The parameters $J_{2}, J_{3}$ and $I_{1}$ represent the invariants of the stress deviator and stress tensor, respectively, characterizing the state of stress considered. The coefficients are material parameters which depend on the strength ratio $f_{c t m} / f_{c m}$ (tensile and compression concrete strength).

\subsection{Stress-strain relation for concrete under compression}

The hardening rule sets the yield surfaces during the plastic deformation and is determined by the effective stress-plastic strain relationship. In the present work a uniaxial stress-strain relationship for compressed concrete is assumed as hardening rule. This stress-strain diagram has the form shown schematically in Figure [3] and is calculated by the following function (CEB [13]):

$$
\sigma_{c}=-\frac{\frac{E_{c i}}{E_{c 1}} \frac{\varepsilon_{c}}{\varepsilon_{c 1}}-\left(\frac{\varepsilon_{c}}{\varepsilon_{c 1}}\right)^{2}}{1+\left(\frac{E_{c i}}{E_{c 1}}-2\right) \frac{\varepsilon_{c}}{\varepsilon_{c 1}}} f_{c m}
$$

where $E_{c i}$ is the concrete tangent modulus, $E_{c i}=-f_{c m} / 0.0022, s_{c}$ is the strength compressive stress, $e_{c}$ is the compression strain and $e_{c 1}=-0.0022$. From a practical viewpoint, an effective plastic strain is computed from the plastic strain tensor. This effective value is therefore used in (35) to update the hardening parameter $\sigma_{c}$.

\subsection{Modeling of cracked concrete - Hinton [14]}

Probably the main feature of plain concrete material behavior is its low tensile strength, which results in tensile cracking at very low stress compared with the failure stress in compression. In the finite element 
context two main approaches have been used for crack representation, the discrete crack model that represents the individual cracks as actual discontinuities in the finite element mesh; the smeared crack model in which the cracked concrete is assumed to remain a continuum and the material properties are modified to account for damage. The second alternative will be adopted in this work.

\subsection{The smeared crack model}

The concrete is initially isotropic, but cracking induces anisotropy. After cracking, the concrete is assumed to become orthotropic, with the principal material axes oriented along the directions of cracking. The material properties depend on the state of strain and stress. The Young's modulus is reduced in the direction perpendicular to the crack plane and Poisson's effect is usually neglected. This approach is computationally attractive, since the topology of the mesh is unchanged throughout the analysis, and only the stress-strain relationship need to be updated when cracking occurs. In order to implement the smeared crack model, the following items have to be applied: a cracking criterion, a strain-softening rule and a model for shear transfer.

In the present work concrete in tension is modeled as a linear elastic-strain softening material. For a previously uncracked sampling point, the principal stresses and their directions are evaluated. If the maximum principal stress exceeds a limiting value, a crack is formed in a plane orthogonal to this stress. So, the behavior of the concrete is no longer isotropic.

Due to bond forces, cracked concrete carries between the cracks a certain amount of tensile stress normal to the cracked plane. The concrete adheres to reinforcing bars and contributes actively to the overall stiffness of the structure. This can be incorporated into the computational model assuming that the loss of tensile strength in concrete occurs gradually and such procedure has been extensively used in computational analysis of reinforced concrete structures. According to Hinton [14] it is easy to choose a tension-stiffening curve that will adequately fit experimental results, but very difficult to make a priori predictions.

For the tensile concrete it will be used the constitutive equation (Eq. 36) adopted by Prates Junior [15], Martinelli [16] and other authors.

$$
\sigma_{i}=\alpha_{t} f_{c i}\left(1-\frac{\varepsilon_{u i}}{0,01}\right)
$$

where $a_{t}$ is the reduction coefficient related to cracking strength and $e_{u i}$ is the strain on direction $i$.

\subsubsection{Shear transfer across the crack}

Experiments show that a considerable amount of shear stress can be transferred across the rough surfaces of cracked concrete. In plain concrete the main shear transfer mechanism is aggregate interlock. In reinforced concrete dowel action will play a significant role, the main variable being the reinforcement ratio.

The above-mentioned mechanisms cannot be directly included in the smeared crack model. A simplified approach is generally employed to take into account the shear transfer capacity of cracked concrete. The process consists of assigning to the shear modulus corresponding to the crack plane a reduced value, $G_{c}$, defined as $G_{c}=b G_{o}$, where $G_{o}$ is the shear modulus of uncracked concrete and $b$ is a reducing factor in the range of zero to one. Hinton [14] relates the value of $b$ to the tensile strain normal to the crack plane. In this work, the following value is used.

$$
\beta=1-\left(\varepsilon_{t} / 0.005\right)^{k_{1}}
$$

where $e_{t}$ is the tensile strain normal to the crack plane and $k_{1}$ is a parameter in the range of 0.3 to 1.0 (used in the present work).

\section{Application}

The applicability and verification of the developed program are demonstrated by comparing the results obtained in this study with experimental results. Bresler-Scordelis beams were used to validate the program coded. They are simply supported, as shown in Figure [4], and refer to a study about shear stress strength, Bresler and Scordelis [17].

\section{Figure 4 - Simply supported beam}

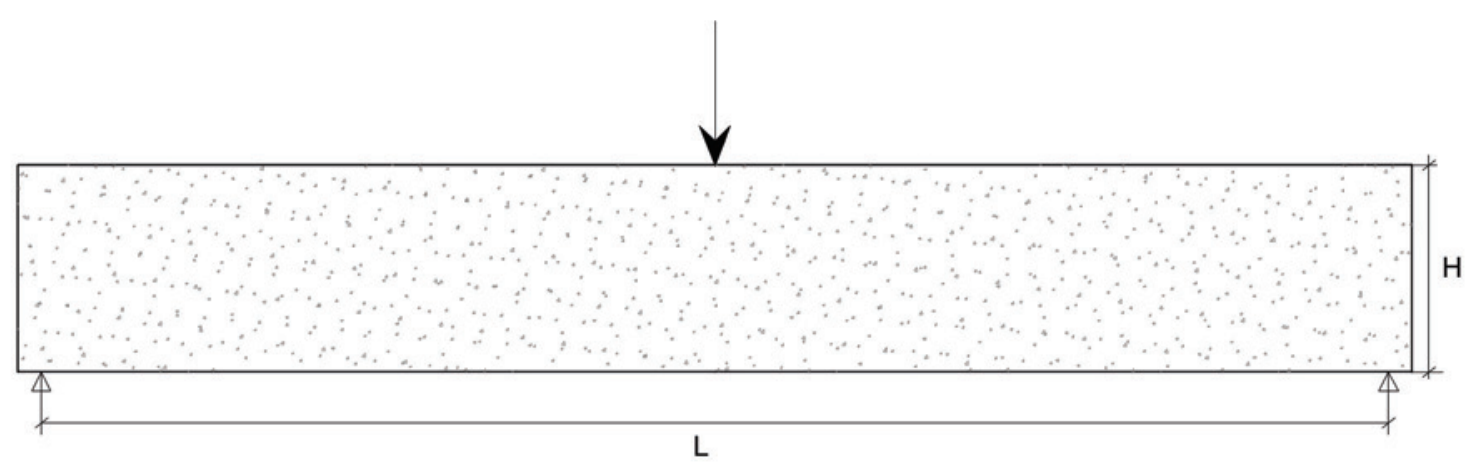




\begin{tabular}{|c|c|c|c|c|c|c|}
\hline \multicolumn{7}{|c|}{ Table 1 - Beam details } \\
\hline Beam & $\begin{array}{c}w \\
(\mathrm{~cm})\end{array}$ & $\begin{array}{c}\mathrm{h} \\
(\mathrm{cm})\end{array}$ & $\underset{(\mathrm{cm})}{\mathrm{L}}$ & $\begin{array}{c}\text { As } \\
\left(\mathrm{cm}^{2}\right)\end{array}$ & $\begin{array}{c}A s^{\prime} \\
\left(\mathrm{cm}^{2}\right)\end{array}$ & Stirrups \\
\hline OAl & 31,0 & 55,6 & 366 & 25,88 & - & - \\
\hline OA2 & 30,5 & 56,1 & 457 & 32,35 & - & - \\
\hline OA3 & 30,7 & 55,6 & 640 & 38,81 & - & - \\
\hline $\mathrm{Al}$ & 30,7 & 55,1 & 366 & 25,88 & 2,53 & $\phi 6,4 c / 21$ \\
\hline $\mathrm{A} 2$ & 30,5 & 55,9 & 457 & 32,35 & 2,53 & $\phi 6,4 c / 21$ \\
\hline $\mathrm{A} 3$ & 30,7 & 56,1 & 640 & 38,81 & 2,53 & $\phi 6,4 c / 21$ \\
\hline $\mathrm{B} 1$ & 23,1 & 55,6 & 366 & 25,88 & 2,53 & $\phi 6,4 \mathrm{c} / 19$ \\
\hline B2 & 22,9 & 56,1 & 457 & 25,88 & 2,53 & $\phi 6,4 c / 19$ \\
\hline B3 & 22,9 & 55,6 & 640 & 32,35 & 2,53 & $\phi 6,4 \mathrm{c} / 19$ \\
\hline $\mathrm{Cl}$ & 23,1 & 55,6 & 366 & 25,88 & 2,53 & $\phi 6,4 c / 21$ \\
\hline $\mathrm{C} 2$ & 22,9 & 56,1 & 457 & 32,35 & 2,53 & $\phi 6,4 c / 21$ \\
\hline C3 & 22,9 & 55,6 & 640 & 38,81 & 2,53 & $\phi 6,4 \mathrm{c} / 21$ \\
\hline
\end{tabular}

Table 2 - Mechanical properties

\begin{tabular}{|ccccccc|}
\hline Beam & $\begin{array}{c}\mathbf{E}_{\mathrm{c}} \\
\left(\mathrm{kN} / \mathrm{cm}^{2}\right)\end{array}$ & $\mathrm{n}$ & alfa & $\begin{array}{c}\mathbf{E}_{\mathrm{s}} \\
\left(\mathrm{kN} / \mathrm{cm}^{2}\right)\end{array}$ & $\begin{array}{c}\mathbf{f}_{\mathrm{c}} \\
\left(\mathrm{kN} / \mathrm{cm}^{2}\right)\end{array}$ & $\begin{array}{c}\mathbf{f}_{\mathrm{f}} \\
\left(\mathrm{kN} / \mathrm{cm}^{2}\right)\end{array}$ \\
\hline OA1 & $3.38 \times 10^{3}$ & 0.2 & 0.4 & $2.05 \times 10^{4}$ & 2,25 & 0,264 \\
OA2 & $3.43 \times 10^{3}$ & 0.2 & 0.4 & $2.05 \times 10^{4}$ & 2,37 & 0,289 \\
OA3 & $3.91 \times 10^{3}$ & 0.2 & 0.4 & $2.05 \times 10^{4}$ & 3,76 & 0,276 \\
A1 & $3.46 \times 10^{3}$ & 0.2 & 0.4 & $2.05 \times 10^{4}$ & 2,41 & 0,257 \\
A2 & $3.46 \times 10^{3}$ & 0.2 & 0.4 & $2.05 \times 10^{4}$ & 2,43 & 0,248 \\
A3 & $3.91 \times 10^{3}$ & 0.2 & 0.4 & $2.05 \times 10^{4}$ & 3,50 & 0,289 \\
B1 & $3.49 \times 10^{3}$ & 0.2 & 0.4 & $2.05 \times 10^{4}$ & 2,48 & 0,266 \\
B2 & $3.41 \times 10^{3}$ & 0.2 & 0.4 & $2.05 \times 10^{4}$ & 2,32 & 0,251 \\
B3 & $3.92 \times 10^{3}$ & 0.2 & 0.4 & $2.05 \times 10^{4}$ & 3,87 & 0,281 \\
C1 & $3.70 \times 10^{3}$ & 0.2 & 0.4 & $2.05 \times 10^{4}$ & 2,96 & 0,281 \\
C2 & $3.44 \times 10^{3}$ & 0.2 & 0.4 & $2.05 \times 10^{4}$ & 2,38 & 0,262 \\
C3 & $3.91 \times 10^{3}$ & 0.2 & 0.4 & $2.05 \times 10^{4}$ & 3,50 & 0,257 \\
\hline
\end{tabular}




\section{Figure 5 - Reinforcement details}
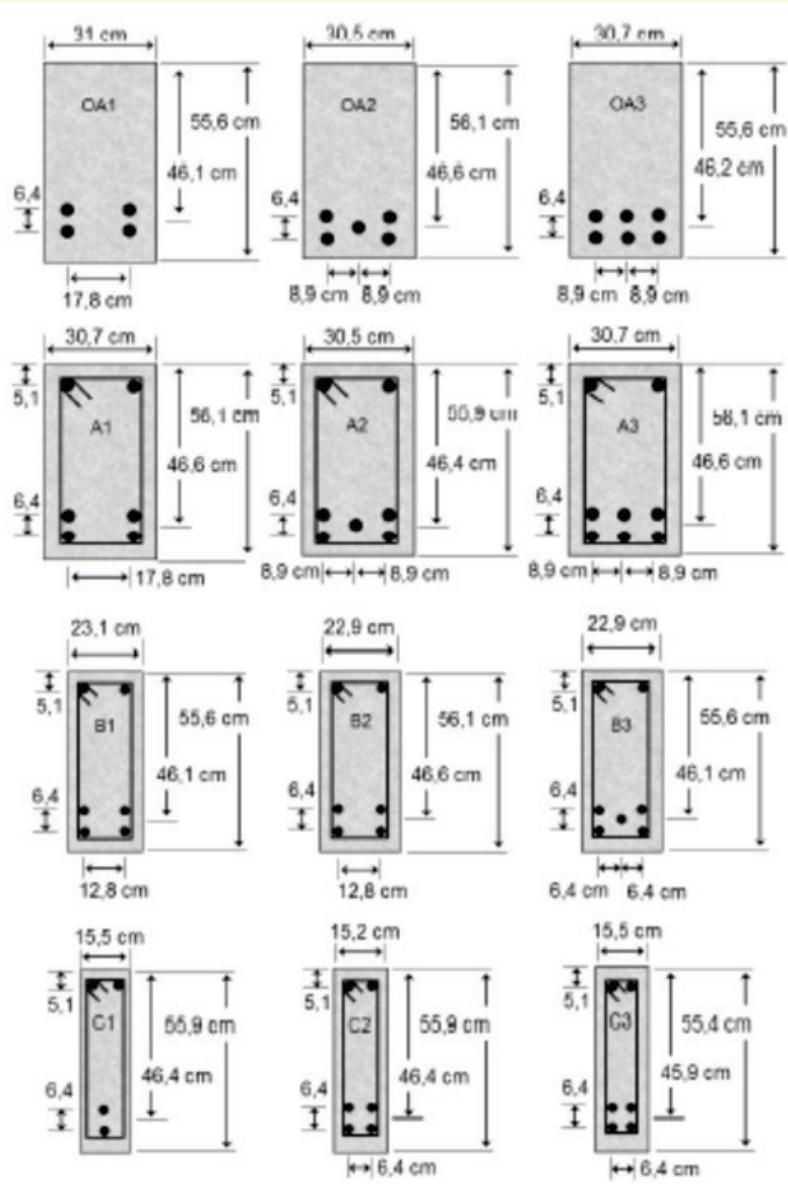

concrete element is also reinforced near the compressive face) and have shear reinforced too. Table [1] presents width ( $w$ ), height $(h)$, length $(L)$, inferior and superior steel area $\left(A_{s}\right.$ and $\left.A_{s}{ }^{\prime}\right)$, stirrups. Table [2] presents mechanical properties of each model. The reinforcement details of each beam are shown in Figure [5].

The finite element mesh used for the simulations consists in thirty 20node hexahedron elements as can be seen in Figure [6]. The hatched elements represent the reinforced elements, in other words, the elements that receive a contribution of the longitudinal reinforcement phase (direction of the $x$ axis). Note that since we have different steel ratios for superior and inferior reinforcement, they will have different volumetric fractions and so will be represented by two distinct phases. For simulating beams from $A, B$ and $C$ groups (also shear reinforced), it is necessary to use a third phase, along y axis direction, for every element in the mesh.

The results of the nonlinear analysis of these beams by using the multiphase model are given in Figures [7], [8] and [9]. As seen from these figures, the load-displacement curves are in good agreement with the experimental results.

\section{Concluding remarks}

A multiphase model for structures of reinforced concrete with per- fect bonding between the steel bars and the matrix of concrete and considering the concrete cracking was introduced. The comparative study performed with the Bresler-Scordelis beams produced results in good agreement with the experimental results. In terms of future development, the model will be extended to include more realistic conditions than perfect bonding, allowing sliding between the matrix phase and the reinforcement phase. Also, assessing the extent of the multiphase zone, which is the size of the concrete structure to be considered as a multiphase model is object of interest.

\section{Acknowledgements}

Finally, my thanks to CNPq (Brazilian National Council for Scientific and Technological Development) for financial support which enabled this work.

\section{References}

[01] FIGUEIREDO, M. P., MAGHOUS, S., CAMPOS FILHO, A. Elastoplastic multiphase model for reinforced concrete flat slabs. Congresso 
Figure 6 - Finite element mesh and reinforcement phases

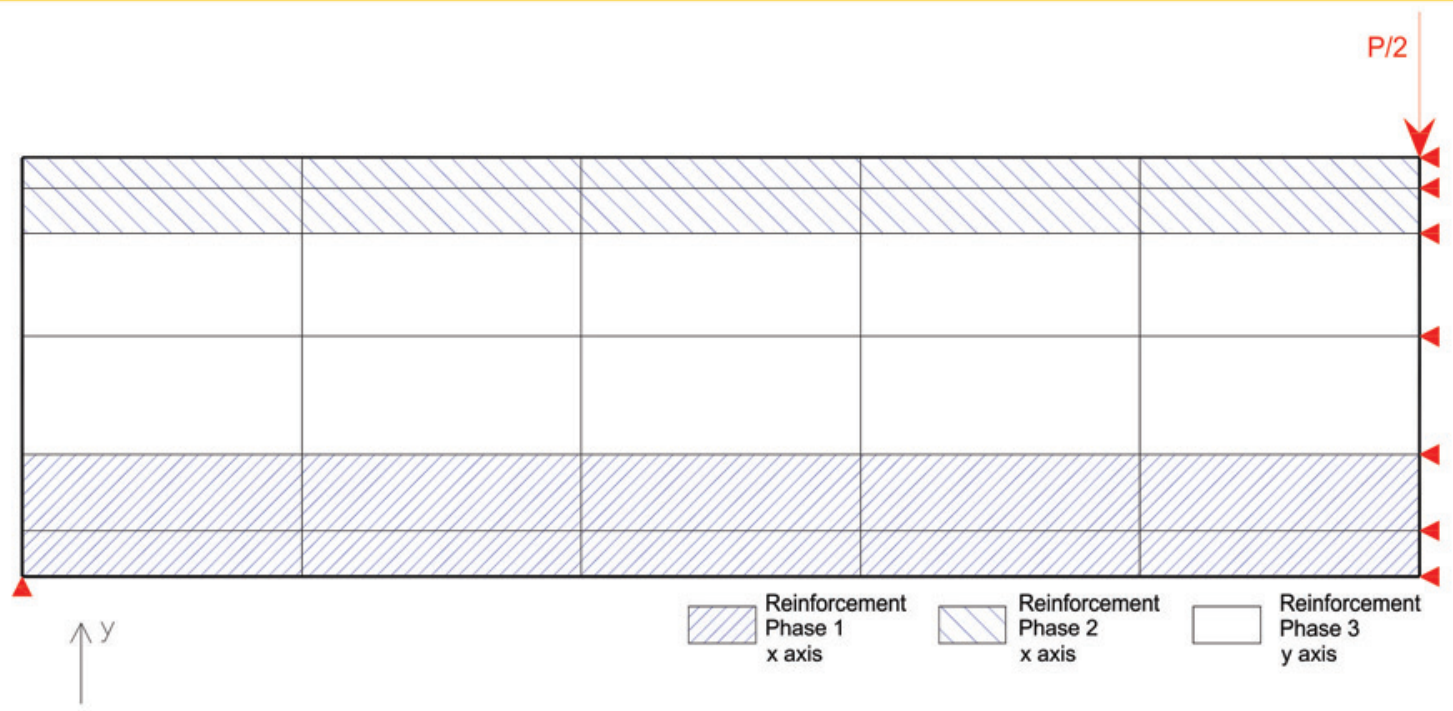

Ibero-Latino-Americano de Métodos Computacionais em Engenharia - CILAMCE, Armação de Búzios, 2009.

[02] COMITÉ EURO-INTERNATIONAL DU BÉTON (CEB). Application of the Finite Element-Method to Two-Dimensional Reinforced Concrete Structures. Paris, 1983. (Bulletin d'Information, 159).
[03] SUDRET, B. Modélisation multiphasique des ouvrages renforcés par inclusions. Thèse de doctorat de l'École Nationale des Ponts et Chaussés, Paris, 1999.

[04] BENNIS, M. Un modèle multiphasique pour le calcul des ouvrages renforcés par inclusions, avec prise en compte de l'interaction

\section{Figure 7 - Load-displacement curves, beams series 1}

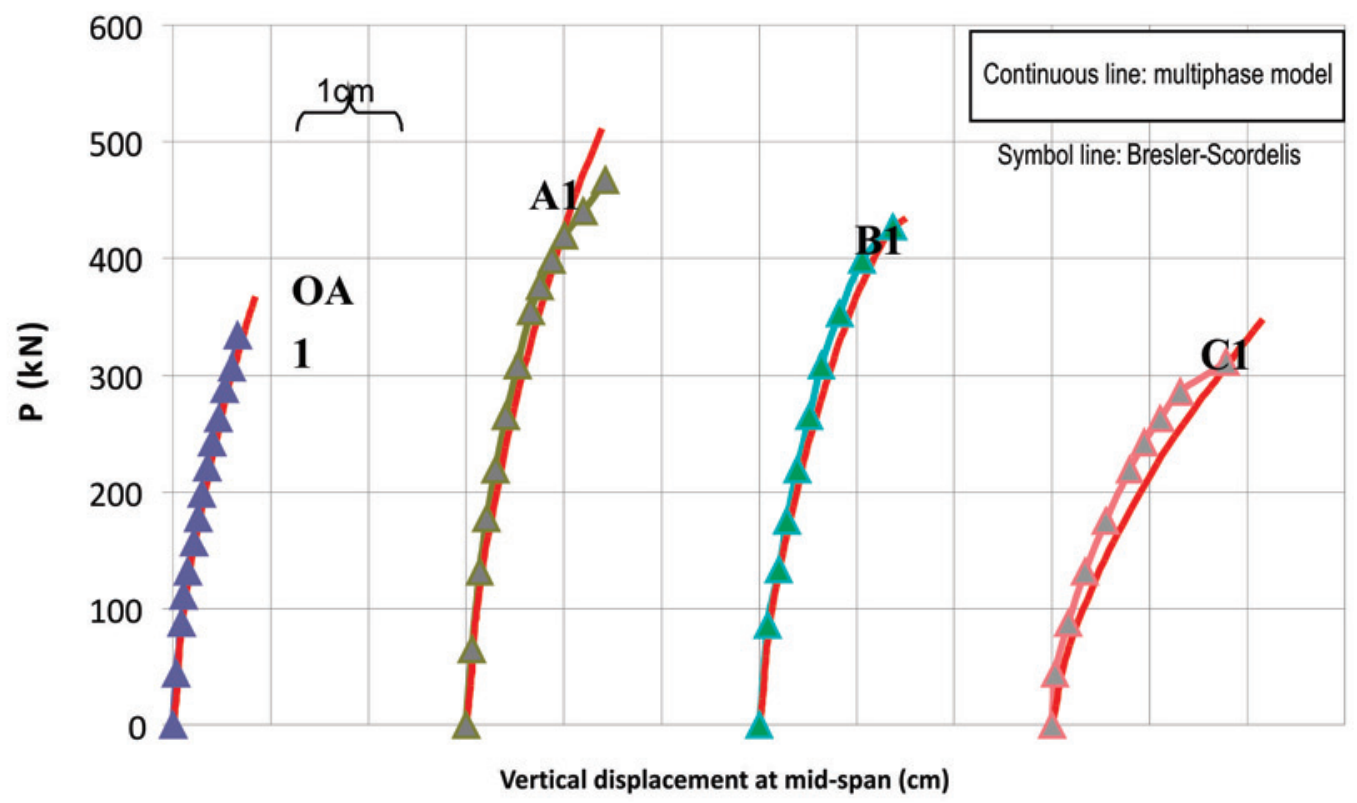


matrice/inclusions. Thèse de doctorat de l'École Nationale des Ponts et Chaussés, Paris, 2002.

[05] HASSEN, G. Modélisation multiphasique pour le calcul des ouvrages renforcés par inclusion rigides. Thèse de doctorat de l'École Nationale des Ponts et Chaussés, Paris, 2006.

Figure 8 - Load-displacement curves, beams series 2

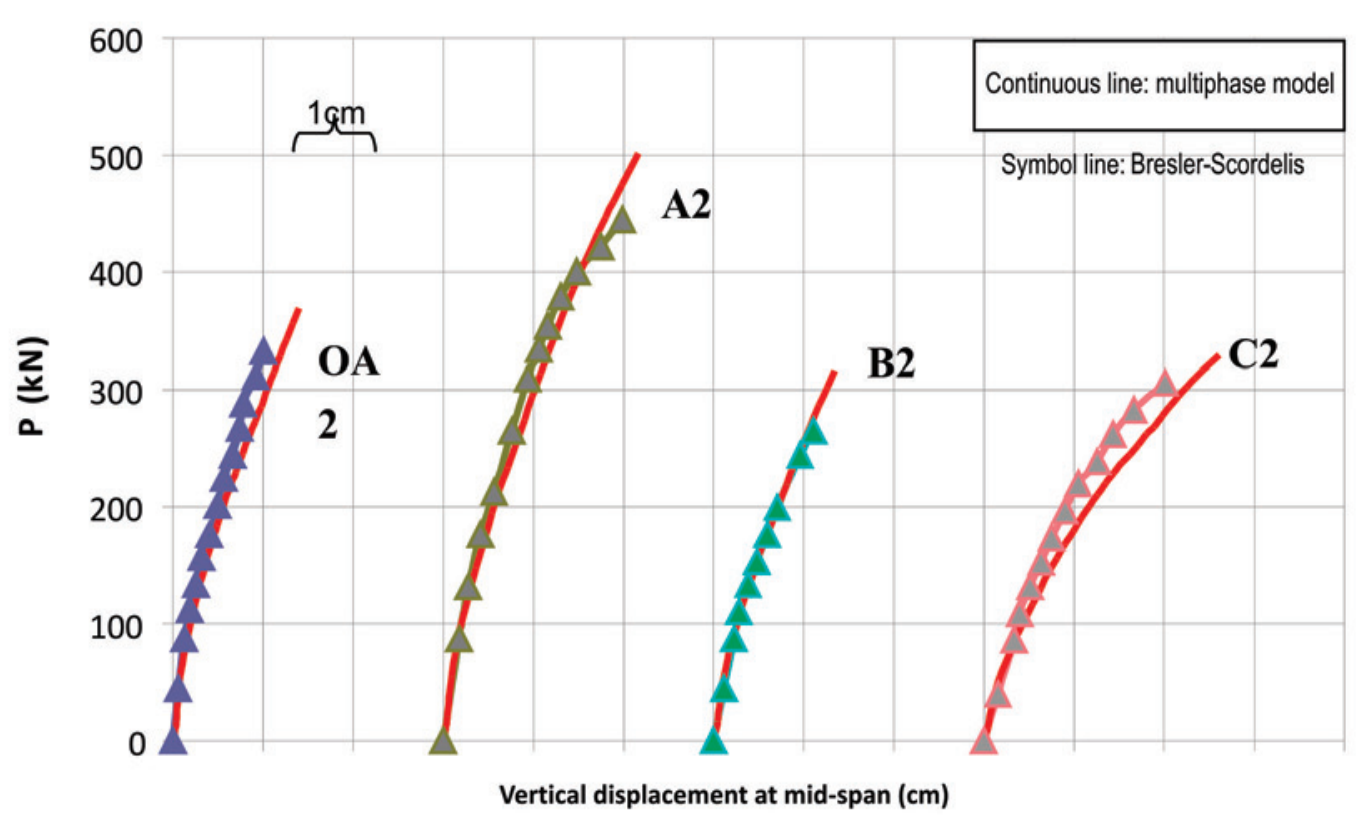

Figure 9 - Load-displacement curves, beams series 3

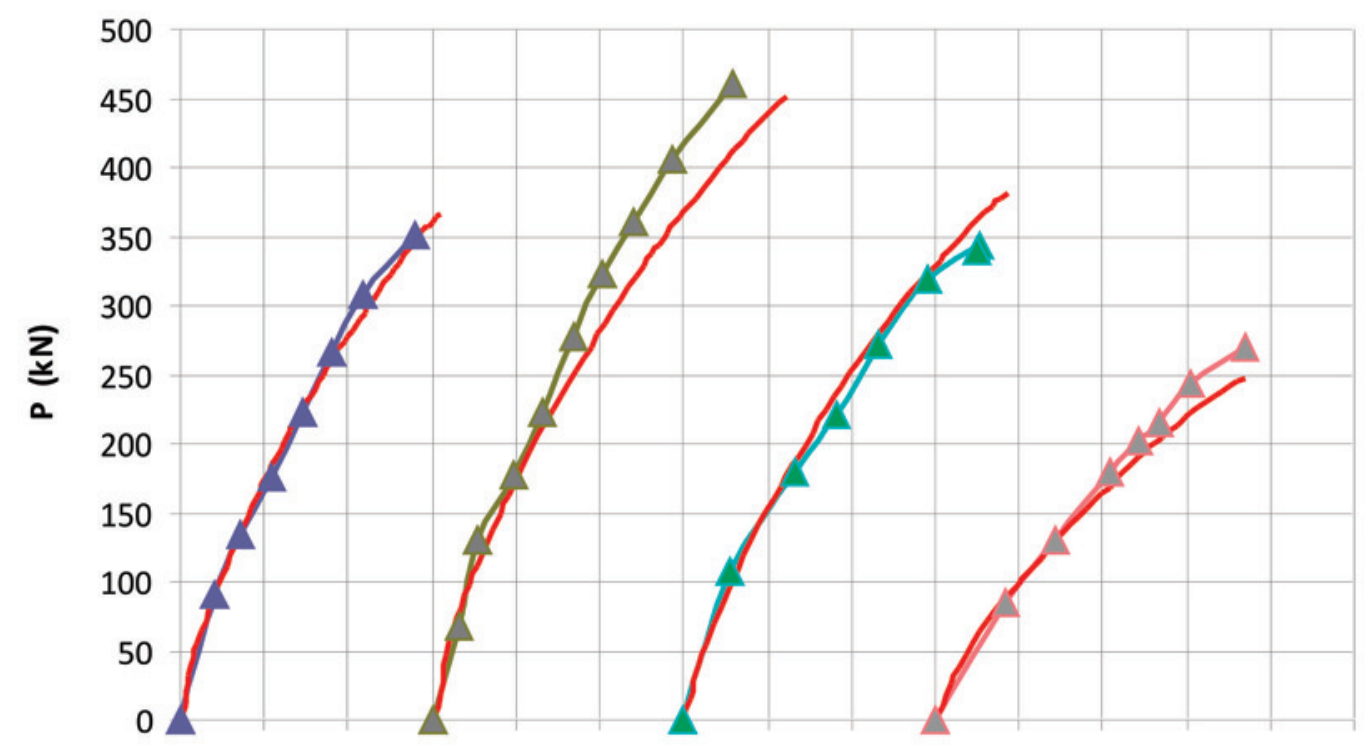

Vertical displacement at mid-span (cm) 
[06] de BUHAN, P., SUDRET, B. Multiphase model for inclusion-reinforced geostructures Application to rock-bolted tunnels and piled raft foundations. International Journal for numerical and analytical methods in geomechanics. 2001, pp 155-182.

[07] HASSEN, G., de BUHAN, P. A two-phase model and related numerical tool for the design of soil structures reinforced by stiff linear inclusions. European Journal of Mechanics A/Solids. 2005, pp 987-1001.

[08] TRUESDEL, C., TOUPIN, R. The classical field theory, Encyclopedia of Physics, vol. III/1, Springer Verlag, Berlin, 1960.

[09] BEDFORD A., DRUMHELLER D. Recent advances in theories of immiscible and structured mixtures. Int. J. Eng. Sci., 21, 863-960, 1983.

[10] OLIVER, J ; LINERO, D ; HUESPE, A ; MANZOLI, $O$. Two-dimensional modeling of material failure in reinforced concrete by means of a continuum strong discontinuity approach. Computer Methods in Applied Mechanics and Engineering, v. 197, p. 332-348, 2008.

[11] MANZOLI, O. L. ; OLIVER, J. ; DIAZ, G. ; HUESPE, A. E. . Three-dimensional analysis of reinforced concrete members via embedded discontinuity finite elements. Revista IBRACON de Estruturas e Materiais, v. 1, p. 58-83, 2008.

[12] SIMO, J. C., HUGHES, T. J. R. Computational Inelasticity. Springer, Berlin, 1998.

[13] COMITÉ EURO-INTERNATIONAL DU BÉTON (CEB). CEB-FIP Model Code 1990. Paris, 1990.

[14] HINTON, E. Numerical methods and software for dynamic analysis of plates and shells. Swansea, U. K. : Pineridge Press, 1988. ix, 550 p. : il.

[15] PRATES JÚNIOR, N. P. Um modelo elasto-viscoplástico para análise de peças de concreto estrutural, submetidas a estados planos de tensão, através do método dos elementos finitos. Dissertação de Mestradado na Universidade Federal do Rio Grande do Sul, Porto Alegre, 1992.

[16] MARTINELLI, M. Modelagem de situações de punção em lajes de concreto armado através do método dos elementos finitos. Dissertação de Mestradado na Universidade Federal do Rio Grande do Sul, Porto Alegre, 2003.

[17] BRESLER, B., SCORDELIS, A. C. Shear strength reinforced concrete beams. ACI Journal, v. 60, n.1, p. 51-72, 1963. 